\title{
Characterization of quaternary chalcogenide As-Ge-Te-Si thin films
}

\author{
H.H. Amer ${ }^{1}$, M. Elkordy ${ }^{2}$, M. Zien ${ }^{2}$, A. Dahshan ${ }^{3}$, R.A. Elshamy ${ }^{2 *}$ \\ ${ }^{1}$ Solid State Department, National Center for Radiation Research and Technology, \\ Nasr City, Cairo, Egypt \\ ${ }^{2}$ Electronics and Communication Department, Faculty of Electronic Engineering, \\ Menofia University, Egypt \\ ${ }^{3}$ Department of Physics, Faculty of Science, Port Said University, Port Said, Egypt \\ ${ }^{2 *}$ E-mail: randa.aly72@yahoo.com
}

\begin{abstract}
Investigated in this paper is the effect of replacement of Te by Si on the optical gap and some other physical operation parameters of quaternary chalcogenide $\mathrm{As}_{30} \mathrm{Ge}_{10} \mathrm{Te}_{60-\mathrm{x}} \mathrm{Si}_{\mathrm{x}}$ (where $\mathrm{x}=0,5,10,12$ and 20 at.\%) thin films. Thin films with the thickness 100-200 nm of $\mathrm{As}_{30} \mathrm{Ge}_{10} \mathrm{Te}_{60-\mathrm{x}} \mathrm{Si}_{\mathrm{x}}$ were prepared using thermal evaporation of bulk samples. Increasing $\mathrm{Si}$ content was found to affect the average heat of atomization, average coordination number, number of constraints and cohesive energy of the $\mathrm{As}_{30} \mathrm{Ge}_{10} \mathrm{Te}_{60-\mathrm{x}} \mathrm{Si}_{\mathrm{x}}$ alloys. Optical absorption is due to allowed non-direct transition, and the energy gap increases with increasing $\mathrm{Si}$ content. The chemical bond approach has been applied successfully to interpret the increase in the optical gap with increasing silicon content.
\end{abstract}

Keywords: thin films, optical gap, Si material, radiation effects, cohesive energy.

Manuscript received 09.03.11; accepted for publication 14.09.11; published online 21.09.11.

\section{Introduction}

Chalcogenide glasses are a recognized group of inorganic glassy materials which always contain one or more chalcogen elements $\mathrm{S}$, Se, or Te but not $\mathrm{O}$, in conjunction with more electropositive elements as As, $\mathrm{Sb}$, and $\mathrm{Bi}$. Chalcogen glasses are generally less robust, weakly bonded materials than oxide glasses.

Initially, glasses containing chalcogen elements were the subject of study owing to their interesting semiconducting properties, and more recently for their applications in optical recording [1,2], technological applications, like optical imaging or storage media [3] and in the field of infrared optical transmitting materials, fiber optics and memory devices [4]. The absence of long-range order of chalcogenide glassy semiconductors allows modification of their optical properties to a specific technological application by continuously changing their chemical composition $[5,6]$. Hence, studying the dependence of their optical properties on composition is important to improve technological application $[7,8]$. As chalcogenide glassy semiconductors, the physical properties of $\mathrm{As}-\mathrm{Te}-\mathrm{Si}$ and $\mathrm{Ge}-\mathrm{Te}-\mathrm{Si}$ are strongly dependent on composition, thus composition is especially important in studying their physical properties. In fact, the chemical bond approach was very useful in predicting the semiconductor properties of different compounds and crystal classes [9]. The present study investigates the influence of addition of $\mathrm{Si}(0,5,10,12$ and 20 at.\%), which is lower in atomic weight than $\mathrm{Te}$, on the optical properties of new, amorphous $\mathrm{As}_{30} \mathrm{Ge}_{10} \mathrm{Te}_{60-\mathrm{x}} \mathrm{Si}_{\mathrm{x}}$ thin films. In addition, the optical band gap $\left(E_{g}\right)$, average coordination numbers $\left(N_{c o}\right)$ and average heat of atomization $\left(H_{s}\right)$ of the $\mathrm{As}_{30} \mathrm{Ge}_{10} \mathrm{Te}_{60-\mathrm{x}} \mathrm{Si}_{\mathrm{x}}$ glasses have been examined theoretically. The results were interpreted in terms of the chemical bond approach used to estimate the cohesive energies of the glasses under investigation.

\section{Experimental details}

Different compositions of bulk $\mathrm{As}_{30} \mathrm{Ge}_{10} \mathrm{Te}_{60-\mathrm{x}} \mathrm{Si}_{\mathrm{x}}$ (where $\mathrm{x}=0,5,10,12,20$ at.\%) chalcogenide glasses were prepared from high-purity $(99.999 \%) \mathrm{As}, \mathrm{Ge}, \mathrm{Te}$ 
and Si by using the melt-quench technique. Appropriate proportions of the raw materials were weighed and sealed into silica ampoules under vacuum of $\approx 10^{-4} \mathrm{~Pa}$, which were then heated gradually up to a temperature of $1125 \mathrm{~K}$ within $1 \mathrm{~h}$ and kept constant for $8 \mathrm{~h}$. Throughout the heating process, the ampoules were regularly shaken to ensure homogeneity and then quenched in ice-cold water to avoid crystallization.

Thin films of $\mathrm{As}_{30} \mathrm{Ge}_{10} \mathrm{Te}_{60-\mathrm{x}} \mathrm{Si}_{\mathrm{x}}$ were prepared by thermal evaporation of the bulk samples. The thermal evaporation process was performed inside the coating system Edward $306 \mathrm{E}$ at the pressure close to $10^{-4} \mathrm{~Pa}$. During the deposition process (at normal incidence), substrates were suitably rotated to obtain films of uniform thickness. The film thickness was controlled within the range $100-200 \mathrm{~nm}$ using a quartz crystal thickness monitor Edward FTM5. The elemental compositions of the investigated specimens were checked using the energy dispersive X-ray spectroscopy (Link Analytical Edx). Deviations in the elemental composition of the evaporated thin films from the initial bulk specimens did not exceed 1.0 at.\%. The amorphous state of the films was checked using an X-ray diffractometer (Philips type 1710 with $\mathrm{Cu}$ as a target and $\mathrm{Ni}$ as a filter; $\lambda=1.5418 \AA$ ). Absence of crystalline peaks confirmed the glassy state of the prepared samples. The double beam spectrophotometer Shimadzu 2101 UV - VIS was used to measure reflectance and transmittance for the prepared films in the spectral wavelength range 200 to $1100 \mathrm{~nm}$.

\section{Simulation results and discussion}

Ioffe and Regel [10] suggested that the bonding character in the nearest neighbor region, which is described by the coordination number (the degree of cross linking), characterizes the electronic properties of the semiconducting materials. It is well known that the coordination number of covalently bonded atoms in glass is given by the so-called $8-N$ rule, where $N$ is the number of outer-shell electrons [11]. The numbers of the nearest neighbor atoms for $\mathrm{As}, \mathrm{Ge}, \mathrm{Te}$ and $\mathrm{Si}$ are calculated and listed in Table 1.

The average coordination number is defined simply as the atom-averaged covalent coordination of the constituents [12]. In the quaternary compounds $\mathrm{A}_{\alpha} \mathrm{B}_{\beta} \mathrm{C}_{\gamma} \mathrm{D}_{\lambda}$ the averaged coordination number is generalized as:

$$
N_{c o}=\frac{\alpha N_{c o}(A)+\beta N_{c o}(B)+\gamma N_{c o}(C)+\lambda N_{c o}(D)}{\alpha+\beta+\gamma+\lambda} .
$$

For our compound the average coordination number is given by the following $2^{\text {nd }}$ relation [13]

$N_{c o}=2 x \mathrm{Te}+3 x \mathrm{As}+4 x \mathrm{Ge}+4 x \mathrm{Si}$.

The degree of cross linking has a profound effect on the thermal and mechanical properties of chalcogenide glasses, because increasing the cross linking makes the atoms become more tightly bound [14].

The determination of $N_{c o}$ allows estimation of the number of constraints $\left(N_{s}\right)$. This parameter is closely related to the glass-transition temperature and associated properties. For a material with the coordination number $N_{c o}, N_{s}$ can be expressed as the sum of the radial and angular valence force constraints [15]:

$$
N_{s}=\frac{N_{c o}}{2}+\left(2 N_{c o}-3\right) \text {. }
$$

The calculated values of $N_{c o}$ and $N_{s}$ for the $\mathrm{As}_{30} \mathrm{Ge}_{10} \mathrm{Te}_{60-\mathrm{x}} \mathrm{Si}_{\mathrm{x}}$ system are given in Table 2. The parameter $r$, which determines the deviation of stoichiometry and is expressed by the ratio of the covalent bonding possibilities of chalcogen atoms to that of non-chalcogen atoms, was calculated using the following relation $[16,17]$ :

$$
r=\frac{(60-x) N_{c o}(\mathrm{Te})}{30 N_{c o}(\mathrm{As})+10 N_{c o}(\mathrm{Ge})+x N_{c o}(\mathrm{Si})} .
$$

The calculated values of $r$ for $\mathrm{As}_{30} \mathrm{Ge}_{10} \mathrm{Te}_{60-\mathrm{x}} \mathrm{Si}_{\mathrm{x}}$ system are also given in Table 2 .

According to Pauling [18], the heat of atomization $H_{s}(A-B)$ at standard temperature and pressure of a binary semiconductor formed from atoms $A$ and $B$ is the sum of the heats of formation $\Delta H$ and the average of the heats of atomization $H_{s}^{A}$ and $H_{s}^{B}$ corresponding to the average non-polar bond energy of the two atoms $[19,20]$ :

Table 1. Values of optical band gap, density, coordination number, heat of atomization $\left(H_{s}\right)$, bond energy and electronegativities of As, Ge, Te, Si used for calculations.

\begin{tabular}{|l|c|c|c|c|}
\hline & $\mathrm{As}$ & $\mathrm{Ge}$ & $\mathrm{Te}$ & $\mathrm{Si}$ \\
\hline Energy gap $(\mathrm{eV})$ & 1.15 & 0.95 & 0.65 & 1.65 \\
\hline Density $\left(\mathrm{g} / \mathrm{cm}^{3}\right)$ & 4.7 & 5 & 6 & 2 \\
\hline Coordination number & 3 & 4 & 2 & 4 \\
\hline$H_{s}(\mathrm{kcal} / \mathrm{g}$ atom) & 69 & 90 & 46 & 108 \\
\hline Bond energy $(\mathrm{kcal} / \mathrm{mol})$ & 32.1 & 37.6 & 33 & 42.2 \\
\hline Electronegativity & 2.18 & 2.01 & 2.1 & 1.8 \\
\hline
\end{tabular}


Table 2. Some of physical parameters as a function of the $\mathrm{Si}$ content for $\mathrm{As}_{30} \mathrm{Ge}_{10} \mathrm{Te}_{60-\mathrm{x}} \mathrm{Si}_{\mathrm{x}}$ (where $\mathrm{x}=\mathbf{0 , 5}, 10,12$, 20 at.\%) specimens.

\begin{tabular}{|c|c|c|c|c|c|c|c|}
\hline Composition & $N_{c o}$ & $N_{s}$ & $R$ & $\begin{array}{c}H_{s} \\
\left(\frac{\mathrm{kcal}}{\mathrm{g} \text { atom }}\right)\end{array}$ & $\begin{array}{c}C E \\
\left(\frac{\mathrm{eV}}{\text { atom }}\right)\end{array}$ & $\begin{array}{c}E_{\text {g,th }} \\
(\mathrm{eV})\end{array}$ & $H_{s} / N_{c o}$ \\
\hline $\mathrm{As}_{30} \mathrm{Ge}_{10} \mathrm{Te}_{60}$ & 2.5 & 3.25 & 0.923 & 57.3 & 3.624 & 0.83 & 22.92 \\
\hline $\mathrm{As}_{30} \mathrm{Ge}_{10} \mathrm{Te}_{55} \mathrm{Si}_{5}$ & 2.6 & 3.5 & 0.733 & 60.4 & 3.848 & 0.88 & 23.23 \\
\hline $\mathrm{As}_{30} \mathrm{Ge}_{10} \mathrm{Te}_{50} \mathrm{Si}_{10}$ & 2.7 & 3.75 & 0.588 & 63.5 & 4.071 & 0.93 & 23.52 \\
\hline $\mathrm{As}_{30} \mathrm{Ge}_{10} \mathrm{Te}_{48} \mathrm{Si}_{12}$ & 2.74 & 3.85 & 0.539 & 64.74 & 4.161 & 0.95 & 23.63 \\
\hline $\mathrm{As}_{30} \mathrm{Ge}_{10} \mathrm{Te}_{40} \mathrm{Si}_{20}$ & 2.9 & 4.25 & 0.381 & 69.7 & 4.517 & 1.03 & 24.03 \\
\hline
\end{tabular}

Table 3. Bond energy, probabilities and relative probabilities for formation of various bonds in $\mathrm{As}-\mathrm{Ge}-\mathrm{Si}-\mathrm{Te}$ glasses, taking the probability of $\mathrm{Si}-\mathrm{Si}$ bonds as unity.

\begin{tabular}{|c|c|c|c|}
\hline Bond & $\begin{array}{c}\text { Bond energy } \\
(\mathrm{kcal} / \mathrm{mol})\end{array}$ & Probability & $\begin{array}{c}\text { Relative probability } \\
\text { (at } T=298.15 \mathrm{~K})\end{array}$ \\
\hline $\mathrm{Si}-\mathrm{Si}$ & 42.20 & $1.03 \times 10^{31}$ & 1 \\
\hline $\mathrm{Ge}-\mathrm{Si}$ & 41.16 & $1.77 \times 10^{30}$ & 0.17 \\
\hline $\mathrm{As}-\mathrm{Si}$ & 41.13 & $1.69 \times 10^{30}$ & 0.16 \\
\hline $\mathrm{Te}-\mathrm{Si}$ & 40.02 & $2.58 \times 10^{29}$ & 0.02 \\
\hline $\mathrm{Ge}-\mathrm{Ge}$ & 37.60 & $4.30 \times 10^{27}$ & $1.16 \times 10^{-4}$ \\
\hline $\mathrm{As}-\mathrm{Ge}$ & 35.61 & $1.48 \times 10^{26}$ & $1.11 \times 10^{-5}$ \\
\hline $\mathrm{Ge}-\mathrm{Te}$ & 35.46 & $1.15 \times 10^{26}$ & $1.73 \times 10^{-7}$ \\
\hline $\mathrm{Te}-\mathrm{Te}$ & 33.00 & $1.79 \times 10^{24}$ & $1.04 \times 10^{-7}$ \\
\hline $\mathrm{As}-\mathrm{Te}$ & 32.70 & $1.08 \times 10^{24}$ & $3.78 \times 10^{-8}$ \\
\hline $\mathrm{As}-\mathrm{As}$ & 32.10 & $3.90 \times 10^{23}$ & \\
\hline
\end{tabular}

$$
H_{s}(A-B)=\Delta H+\frac{1}{2}\left(H_{s}^{A}+H_{s}^{B}\right)
$$

$\Delta H$ is proportional to the square of the difference between the electronegativities $\chi_{A}$ and $\chi_{B}$ of the two atoms:

$$
\Delta H \propto\left(\chi_{A}-\chi_{B}\right)^{2} .
$$

$\Delta H$ that is strongly correlated with the difference in the ionicities of different atoms is small compared to the cohesive energy, because the electronegativities of the constituent elements such as As, Te, Si are very similar. In most cases, the heat of formation of chalcogenide glasses is unknown. In the few materials for which it is known, the heat of formation $\Delta H$ is about $10 \%$ of the heat of atomization and, therefore, can be neglected.

To extend the idea to ternary and higher order semiconductor compounds, the average heat of atomization is defined for a compound $\mathrm{A}_{\alpha} \mathrm{B}_{\beta} \mathrm{C}_{\gamma} \mathrm{D}_{\lambda}$ as $[21,22]$ :

$$
N_{s}=\frac{\alpha H_{s}^{A}+\beta H_{s}^{B}+\gamma H_{s}^{C}+\lambda H_{s}^{D}}{\alpha+\beta+\gamma+\lambda} .
$$

The values of $H_{s}$ for $\mathrm{As}_{30} \mathrm{Ge}_{10} \mathrm{Te}_{60-\mathrm{x}} \mathrm{Si}_{\mathrm{x}}$ alloys obtained using the values of $H_{s}$ of As, Ge, Te and $\mathrm{Sb}$ are given in Table 2. As shown in this table, the values of $H_{s}$ increase with increasing Si content. To correlate $H_{s}$ with $E_{g}$ in non-crystalline solids, it is reasonable to use the average coordination number instead of the isostructure of crystalline semiconductors.

It was found that the variation in the theoretical values of the energy gap $E_{g, t h}$ with composition in quaternary alloys can be described [23] by the following simple relation:

$$
E_{g A B}(Y)=Y E_{g A}+(1-Y) E_{g B},
$$

where $Y$ is the volume fraction of element. For quaternary alloys:

$$
E_{g, t h}(A B C D)=a E_{g}(A)+b E_{g}(B)+
$$$$
+c E_{g}(C)+d E_{g}(D) \text {, }
$$

where $a, b, c$, and $d$ are the volume fractions of the elements $A, B, C$ and $D$, respectively. $E_{g}(A), E_{g}(B)$, $E_{g}(C)$, and $E_{g}(D)$ are the corresponding optical gaps. Conversion from a volume fraction to atomic percentage is made using the atomic weights and densities [24] tabulated in Table 1. The calculations of $E_{g, t h}$, based on the above equation for the $\mathrm{As}_{30} \mathrm{Ge}_{10} \mathrm{Te}_{60-\mathrm{x}} \mathrm{Si}_{\mathrm{x}}$ alloys, are given in Table 2 , which reveals that the addition of $\mathrm{Si}$ leads to a change in the considered properties. The increase in $\mathrm{Si}$ leads to increase in $E_{g, t h}$ and $N_{c o}$. The various bond energies of the expected bonds in the system are listed in Table 3. By increasing the $\mathrm{Si}$ content, the average bond strength of the compound decreases, and hence $E_{g}$ will decrease. 


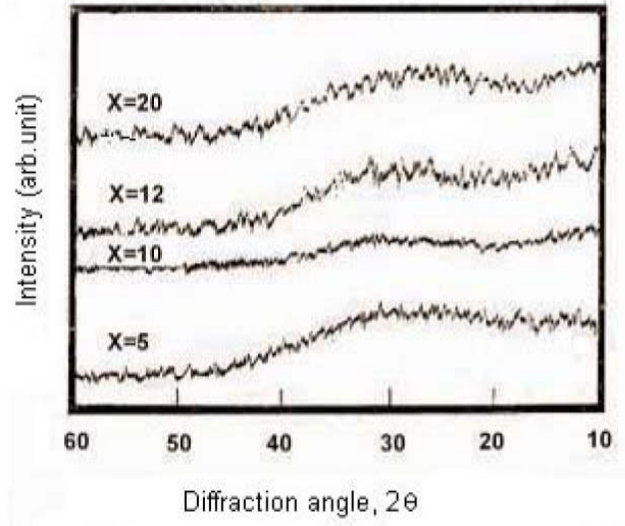

Fig. 1. X-ray diffraction patterns of the amorphous $\mathrm{As}_{30} \mathrm{Ge}_{10} \mathrm{Te}_{60-\mathrm{x}} \mathrm{Si}_{\mathrm{x}}$ (where $\mathrm{x}=0,5,10,12,20$ at.\%) thin films.

To emphasize the relationship between $E_{g}$ and the average bond strength more clearly, $E_{g}$ is compared with $H_{s} / N_{c o}$ which is the average single-bond energy in the alloy. One observes that $E_{g}$, as well as $H_{s} / N_{c o}$ increase with increasing Si content, which suggests that one of the main factors determining $E_{g}$ is the average single bond in the alloy [25]. Fig. 1 shows the X-ray diffraction patterns for $\mathrm{As}_{30} \mathrm{Ge}_{10} \mathrm{Te}_{60-\mathrm{x}} \mathrm{Si}_{\mathrm{x}}$ thin films. The absence of diffraction lines in the X-ray patterns indicates that the films have amorphous structures. Transmission spectra corresponding to the amorphous $\mathrm{As}_{30} \mathrm{Ge}_{10} \mathrm{Te}_{60-\mathrm{x}} \mathrm{Si}_{\mathrm{x}}$ thin films before and after irradiation of 1 and $15 \mathrm{Mrad}$ are plotted in Figs 2, 3, 4 and show a clear ultraviolet shift of the interference-free region with increasing Si content.

The values of the absorption coefficient $\alpha$ for the studied films were calculated from transmittance $T$ and reflectance $R$ using the equation:

$\alpha=\frac{1}{d} \ln \frac{(1-R)^{2}}{T}$,

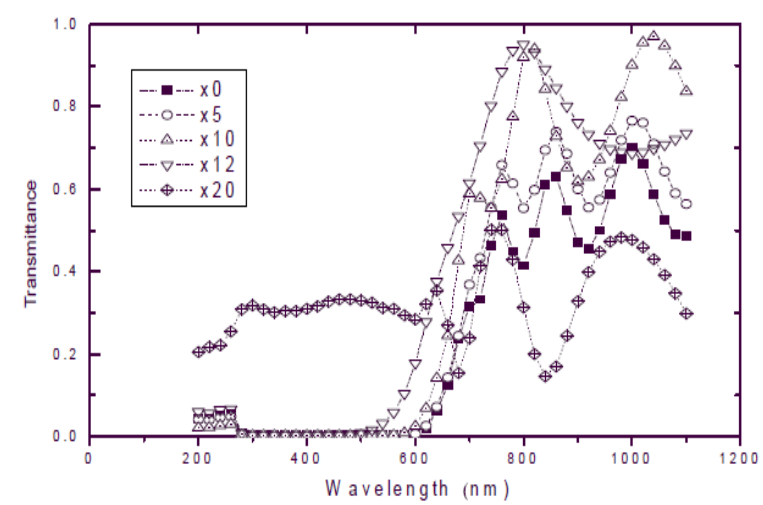

Fig. 2. Transmission spectra for $\mathrm{As}_{30} \mathrm{Ge}_{10} \mathrm{Te}_{60-\mathrm{x}} \mathrm{Si}_{\mathrm{x}}$ (where $\mathrm{x}=0,5,10,12,20$ at.\%) thin films before irradiation. where $d$ is the thickness of the film. According to Tauc's relation $[26,27]$ for the allowed non-direct transition, the photon energy dependence of the absorption coefficient can be described by:

$(\alpha h v)^{1 / 2}=B\left(h v-E_{g}\right)$,

where $B$ is a parameter that depends on the transition probability. Figs 5, 6 and 7 are a typical best fit of $(\alpha h v)^{1 / 2}$ versus photon energy $h v$ for $\mathrm{As}_{30} \mathrm{Ge}_{10} \mathrm{Te}_{60-\mathrm{x}} \mathrm{Si}_{\mathrm{x}}$ thin films before and after the radiation exposures 1 and $15 \mathrm{Mrad}$. The intercepts of the straight lines with the photon energy axis give the values of the optical band gap. The variation in $E_{g}$ as a function of $\mathrm{Si}$ content before and after the radiation exposures 1 and $15 \mathrm{Mrad}$ are shown in Fig. 8. It is clear that $E_{g}$ increases with increasing the Si content of the investigated films. Fig. 9 shows the density of amorphous $\mathrm{As}_{30} \mathrm{Ge}_{10} \mathrm{Te}_{60-\mathrm{x}} \mathrm{Si}_{\mathrm{x}}$ thin film, and it is clear that density decreases with increasing the Si content.

The possible bond distribution at various compositions may be considered using the chemically ordered network (CON) model [28]. This model assumes that: a) atoms combine more favourably with atoms of different kinds than with the same and b) bonds are formed in the sequence of bond energies. The bond energies $D(A-B)$ for heteronuclear bonds have been calculated by using the empirical relation [29]:

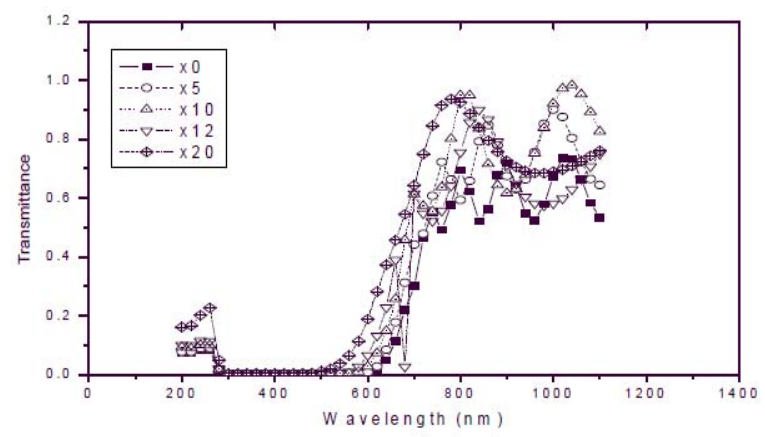

Fig. 3. Transmission spectra for $\mathrm{As}_{30} \mathrm{Ge}_{10} \mathrm{Te}_{60-\mathrm{x}} \mathrm{Si}_{\mathrm{x}}$ (where $\mathrm{x}=0,5,10,12,20$ at.\%) thin films after the radiation exposure 1 Mrad.

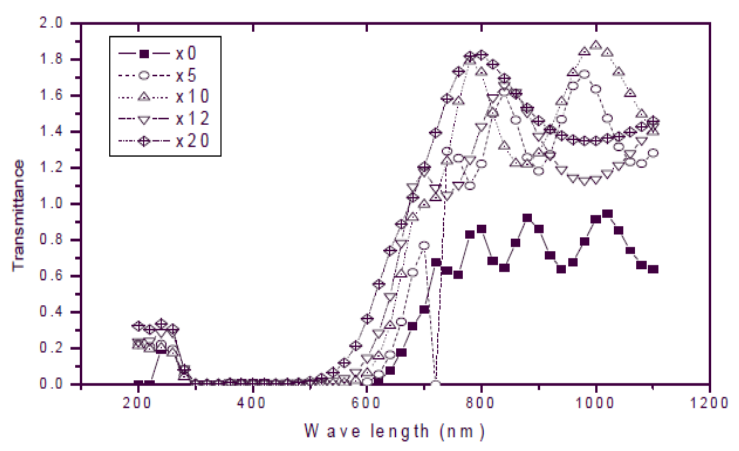

Fig. 4. Transmission spectra for $\mathrm{As}_{30} \mathrm{Ge}_{10} \mathrm{Te}_{60-\mathrm{x}} \mathrm{Si}_{\mathrm{x}}$ (where $\mathrm{x}=0,5,10,12,20$ at.\%) thin films after the radiation exposure $15 \mathrm{Mrad}$. 
$D(A-B)=[D(A-A) \cdot D(B-B)]^{1 / 2}+$

$+30\left(\chi_{A}-\chi_{B}\right)^{2}$,

proposed by Pauling [30], where $D(A-A)$ and $D(B-B)$ are the energies of the homonuclear bonds (in units of $\mathrm{kcal} / \mathrm{mol}$ ) [31]: $\chi_{\mathrm{A}}$ and $\chi_{\mathrm{B}}$ are the electronegatives for the involved atoms [32].

At elevated temperatures, energy bonding effects can influence the film composition. This is because more energy is available to the atoms striking a hot substrate, and they can adjust themselves after striking to form more favorable (i.e. a higher energy) bonds. Thus, for the present material, more silicon might be incorporated into the films at higher temperatures, because it is possible for silicon to form relatively strong bonds with other constituents. This hypothesis is supported by the contents of Table 3 , which lists the relative order of the bond energies of the ten possible bonds in the $\mathrm{Si}-\mathrm{Te}-\mathrm{As}-\mathrm{Ge}$ system. The hetero-atom single-bond energies were calculated from the average of the homoatom single-bond energies for silicon, tellurium, arsenic and germanium, with addition of ionic contribution proportional to the square of the electronegatives difference between the elements.

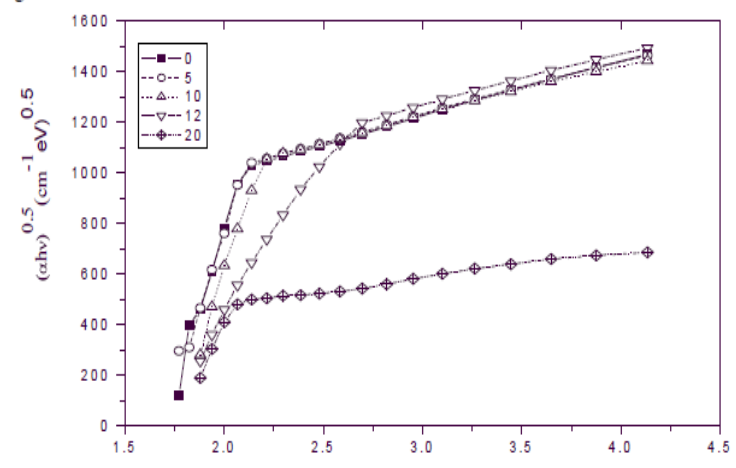

hv (ev)

Fig. 5. Best fit of $(\alpha h v)^{1 / 2}$ versus photon energy $h v$ for $\mathrm{As}_{30} \mathrm{Ge}_{10} \mathrm{Te}_{60-\mathrm{x}} \mathrm{Si}_{\mathrm{x}}$ (where $\mathrm{x}=0,5,10,12,20$ at.\%) thin films before irradiation.

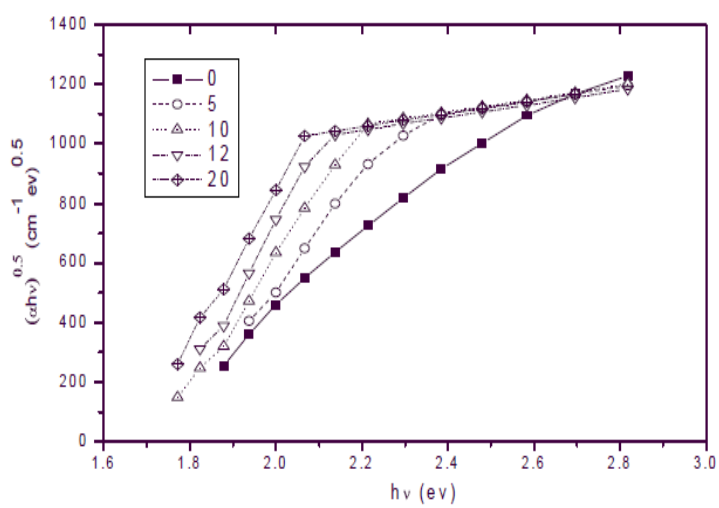

Fig. 6. Best fit of $(\alpha h v)^{1 / 2}$ versus photon energy $h v$ for $\mathrm{As}_{30} \mathrm{Ge}_{10} \mathrm{Te}_{60-\mathrm{x}} \mathrm{Si}_{\mathrm{x}}$ (where $\mathrm{x}=0,5,10,12,20$ at.\%) thin films after the radiation exposure $1 \mathrm{Mrad}$.

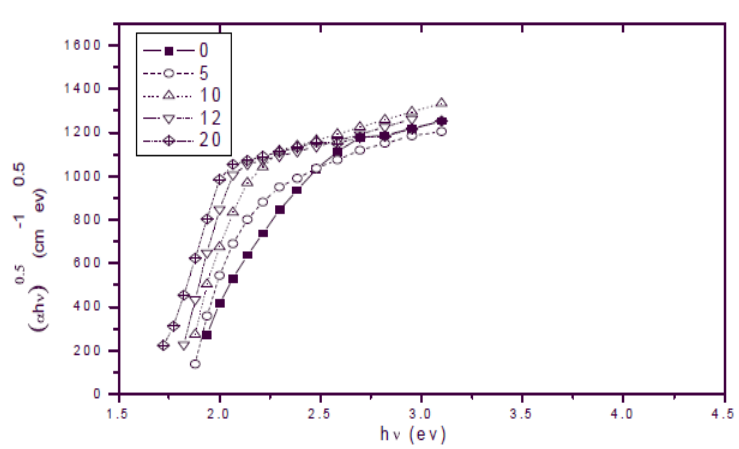

Fig. 7. Best fit of $(\alpha h v)^{1 / 2}$ versus photon energy $h v$ for $\mathrm{As}_{30} \mathrm{Ge}_{10} \mathrm{Te}_{60-\mathrm{x}} \mathrm{Si}_{\mathrm{x}}$ (where $\mathrm{x}=0,5,10,12,20$ at.\%) thin films after the radiation exposure $15 \mathrm{Mrad}$.

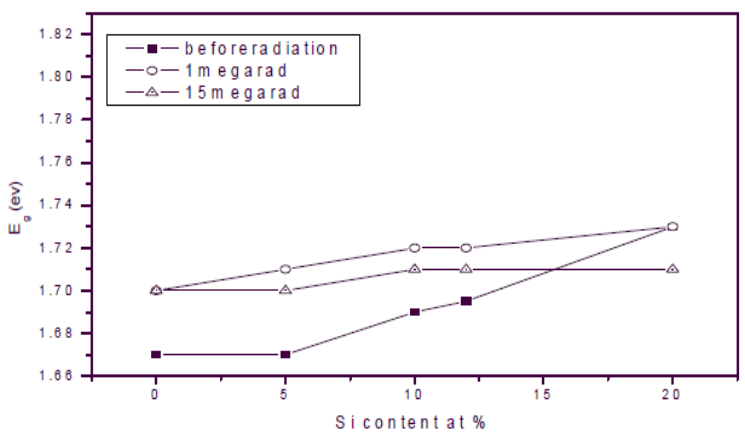

Fig. 8. Variation in the optical band gap $E_{g}$ as a function of $\mathrm{Si}$ content for $\mathrm{As}_{30} \mathrm{Ge}_{10} \mathrm{Te}_{60-\mathrm{x}} \mathrm{Si}_{\mathrm{x}}$ (where $\mathrm{x}=0$, 5, 10, 12, 20 at.\%).

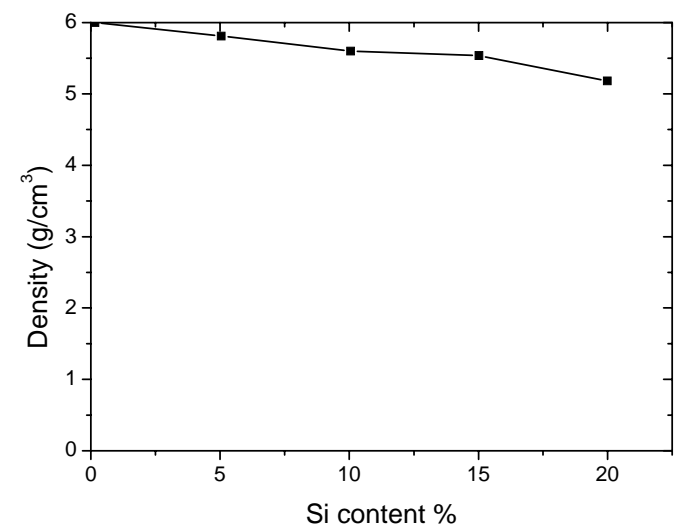

Fig. 9. Density dependence on the $\mathrm{Si}$ content for $\mathrm{As}_{30} \mathrm{Ge}_{10} \mathrm{Te}_{60-\mathrm{x}} \mathrm{Si}_{\mathrm{x}}$ (where $\mathrm{x}=0,5,10,12,20$ at.\%) glasses.

It can be seen from Table 3 that silicon has a better chance of sticking to the growing film at elevated temperatures, as it can form strong bonds with tellurium, the major constituent. However, the As-Te bonds are relatively weak so that a deficiency of arsenic might be expected on energetic grounds.

Knowing the bond energies, we can estimate the cohesive energy $(C E)$, i.e. the stabilized energy of an infinitely large cluster of the material per atom, by summing the bond energies over all the bonds expected 
in the system under test the $C E$ of the prepared samples is evaluated from the following equation [33]

$$
C E=\sum\left(\frac{C_{i} D_{i}}{100}\right),
$$

where $C_{i}$ and $D_{i}$ are the numbers of the expected chemical bonds and the energy of each corresponding bond, respectively. The calculated values of $C E$ for all compositions are summarized in Table 2. CE increases with increasing the Si content. Increasing the Si content leads to an increase in the average molecular weight, which increases the rigidity (strength) of the system.

This approach explains the behaviour in terms of the cohesive energy. It allows determination of the number of possible bonds and their type (heteropolar and homopolar). The energies of various possible bonds in the $\mathrm{As}-\mathrm{Ge}-\mathrm{Si}-\mathrm{Te}$ system are given in Table 3 . Depending on the bond energy $D$, the relative probability of its formation was calculated [34] using the probability function $\exp (D / k T)$ and listed in Table 3 . Bonds, such as $\mathrm{Si}-\mathrm{Si}, \mathrm{Ge}-\mathrm{Ge}, \mathrm{Te}-\mathrm{Te}$, and $\mathrm{As}-\mathrm{As}$ bonds exist with high priority in the $\mathrm{As}-\mathrm{Ge}-\mathrm{Si}-\mathrm{Te}$ system.

\section{Conclusions}

Optical data indicated that the allowed, non-direct gap is responsible for photon absorption in $\mathrm{As}_{30} \mathrm{Ge}_{10} \mathrm{Te}_{60-\mathrm{x}} \mathrm{Si}_{\mathrm{x}}$ thin films. Increasing the $\mathrm{Si}$ content at the expense of $\mathrm{Te}$ atoms increases the optical gap of these films. The values for heat of atomization, coordination number, number of constraints and cohesive energy of $\mathrm{As}_{30} \mathrm{Ge}_{10} \mathrm{Te}_{60-\mathrm{x}} \mathrm{Si}_{\mathrm{x}}$ are dependent on glass composition. The increase in $\mathrm{Si}$ content leads to increase in $E_{g, t h}$, $H_{s} / N_{c o}$ and $N_{c o}$. Cohesive energy increases with increasing the Si content. The chemical-bond approach can be successfully applied to interpret the increase in the optical gap with increasing the Si content.

\section{Acknowledgement}

The authors would like to thank Dr. A. Abdglel, Solid State Physics Department, National Center for Radiation Research and Technology, Atomic Energy Authority, Cairo, Egypt for his help and support.

\section{References}

1. N.A. Goryunova and B.T. Kolomiets // Zhurnal Tekhnich. Fiziki, 25, p. 984 (1955), in Russian.

2. K. Tanaka, Y. Osaka, M. Sugi, et al. // J. NonCryst. Solids, 12, p. 100 (1973).

3. A.E. Owen, A.P. Firth and P.J.S. Ewen // Phil. Mag. B, 52, p. 347 (1985).

4. R. Zallen, Physics of Amorphous Solids. Wiley, New York, 1983.
5. E.A. Davis // J. Non-Cryst. Solids, 71, p. 113 (1985).

6. A.H. Moharram, A.A. Othman, H.H. Amer, et al. // J. Non-Cryst. Solids, 352, p. 2187 (2006).

7. M. Yamaguchi // Phil. Mag. 51, p. 651 (1985).

8. S.S. Fouad, A. Ammar, M. Abo-Ghazala // Physica B, 229, p. 249 (1997).

9. E. Mooser, W.B. Pearson // Prog. Semicond. 5, p. 103 (1960).

10. A.F. Ioffe and A.R. Regel // Prog. Semicond. 4, p. 239 (1960).

11. P. Kumar, K. Singh // Chalcogenide Lett. 4, No.11, p. 127 (2007).

12. A.K. Varshneya, A.N. Sreeram, D.R. Swiler // Phys. Chem. Glasses, 34, p. 179 (1992).

13. S.S. Fouad // Vacuum, 52, p. 505 (1999).

14. G.H. Frischat, U. Brokmeir, A. Rosskamp // J. Non-Cryst. Solids, 50, p. 263 (1982).

15. A. Dahshan, K.A. Aly // Phil. Mag. 88, No.3, p. 361 (2008).

16. L. Tichy and H. Ticha // Mater. Lett. 21, p. 313 (1994).

17. L. Tichy and H. Ticha // J. Non-Cryst. Solids, 189, p. 141 (1995).

18. L. Pauling // J. Phys. Chem. 58, p. 662 (1954); The Nature of the Chemical Bond. New York, Cornell University Press, 1960.

19. S.A. Fayek and S.S. Fouad // Vacuum, 52, p. 359 (1998).

20. L. Brewer, Electronic Structure and Alloy Chemistry of the Transition Elements, Beck P.A. (editor). InterScience, New York, 1963, p. 222.

21. N.F. Mott, E.A. Davis, R.A. Street // Phil. Mag. 32, p. 961 (1975).

22. M.F. Thorpe // J. Non-Cryst. Solids, 182, p. 135 (1995).

23. S.S. Fouad // Vacuum, 52, p. 505 (1999).

24. S. Mahadevan, A. Giridhar and A.K. Singh // J. Non-Cryst. Solids, 169, p. 133 (1994).

25. S.S. Fouad, A.H. Ammar and M. Abo-Ghazala // Vacuum, 48, p. 181 (1997).

26. H. Fritzsche // Phil. Mag. B, 68, p. 561 (1993).

27. A. Dahshan, H.H. Amer and K.A. Aly // J. Phys. D: Appl. Phys. 41, 215401 (2008).

28. S.R. Elliot, Physics of Amorphous Solids. Longman Inc, New York, 134 (1984).

29. P. Sharma, M. Vashistha and I.P. Jain // Chalcogenide Lett. 2(11), p. 115 (2005).

30. L. Pauling, The Nature of the Chemical Bond, $3^{\text {rd }}$ ed. Cornell University Press, NY, 1960, p. 91.

31. L. Tichy, A. Triska, H. Ticha, et al. // Solid State Communs. 41, p. 751 (1982).

32. J. Bicermo and S.R. Ovshinsky // J. Non-Cryst. Solids, 74, p. 75 (1985).

33. S.A. Fayek // J. Phys. Chem. Solids, 62, p. 653 (2001).

34. D.R. Goyal and A.S. Maan // J. Non-Cryst. Solids, 183, p. 182 (1995). 